\title{
Do We have an Aimer to put the Tibial and Femoral Tunnels in the Same Line to reduce Mechanical Strain in Reconstructed Anterior Cruciate Ligament?
}

\author{
Khalifa Elmajri
}

\begin{abstract}
The strain between the ACL graft tissue and the osteochondral tissue at the tunnel entrances would lead to postoperative deviation of the femoral and/or tibial insertion of the ACL graft. Postoperative changes of the $3 \mathrm{D}$ orientation of the ACL graft affect its physiometry leading to failure of graft tension. A conception of an aimer is suggested to insure straightening of the intraosseous (tibial and femoral) and intra-articular parts of the graft at the tunnel entry point to overcome the postoperative angulation of intraosseous and intra-articular graft parts
\end{abstract}

Keywords: Anterior cruciate ligament, Knee, Tunnel.

How to cite this article: Elmajri K. Do We have an Aimer to put the Tibial and Femoral Tunnels in the Same Line to reduce Mechanical Strain in Reconstructed Anterior Cruciate Ligament? Int J Recent Surg Med Sci 2017;3(2):130-132.

Source of support: Nil

Conflict of interest: None

\section{INTRODUCTION}

Surgical techniques as well as the use of proper instrumentation augment the long-term results of anterior cruciate ligament (ACL) reconstruction operation. Braiding the strands, ${ }^{1}$ saving the ACL remnant, ${ }^{2}$ tibial tunnel independent technique or classical transtibial technique, ${ }^{3}$ bone tendon or bone tendon bone, single bundle or double bundle or double bundle double tunnel, immobilization period, knee flexion angle during immobilization, early or delayed rehabilitation, and using biological healing promotion are among them.

The native ACL differs from the reconstructed ACL as it has no tunnel and is inserted on the osteochondral tissue of the tibia and femur. ${ }^{4}$

The three-dimensional (3D) orientation of the native ACL is mandatory to perform its function. The reconstructed ACL (ACL graft) is placed in an orientation using tunnels, but still there is no consensus about the

\section{Fellow}

Department of Orthopedics, Center Albert Trillat, Croix-Rousse Hospital, Lyon, France

Corresponding Author: Khalifa Elmajri, Faculty of Medical Technology, Zohour Street, Derna, Libya, Phone: +218910523440, e-mail: kelmajri@gmail.com technique, which yields anatomic placement. Up to 70 to $80 \%$ of failure of ACL reconstruction may involve nonanatomical tunnel placement. ${ }^{5}$

One of the causes would be the postoperative deviation of the femoral and/or tibial insertion of the ACL to one direction (anteriorly, posteriorly, medially, and laterally). As the entry point of tibial and femoral tunnels will be the future insertion of the reconstructed $\mathrm{ACL}$, this deviation will change the $3 \mathrm{D}$ orientation of the ACL and affect its physiometry leading to failure of graft tension.

The critical decrease in mechanical properties of the graft was attributed to the properties of the link between the graft at its tunnel entrance site which was found weakest during the early healing stage of the graft and the most affected region of the graft was the tendon-bone interface in intra-articular environment. ${ }^{6}$

Changes of the insertion sites of the graft, outside the tunnel (intra-articular) and inside the tunnel (intraosseous), can be a cause of graft properties alteration because both will dilate as a part of its healing process during the healing period. From the theoretical point of view - the tension between these two parts of the graft is converted into compression force on the osteochondral tissue at the tunnel entrance leading to erosion of the osteochondral tissues at the entry point of the graft; the new insertion will be moved toward the direction of the maximum strain at the tunnel entrance. At the tunnel entrances and during the early healing period, the maximum mechanical strain (tension force) of the graft, at certain knee flexion angle, is received by the osteochondral tissues as a (compression force) on one side of the tunnel entrances according to the direction of the angle between the intraarticular and intraosseous parts of the graft. To avoid this, we have to ensure the straightening of all parts of the graft at knee flexion where maximum strain is expected considering the postoperative individual activities. ${ }^{7,8}$

The expected maximum strain (between 10 and $30^{\circ}$ of knee flexion) would lead to the erosion of the entry point boundary and deviation of the new insertion of the graft toward the direction of the strain (for the single bundle techniques, the greatest tibial translation is between 20 and $45^{\circ}$ of knee flexion). This deviation will modify the ultimate position of the insertion of the new ACL 


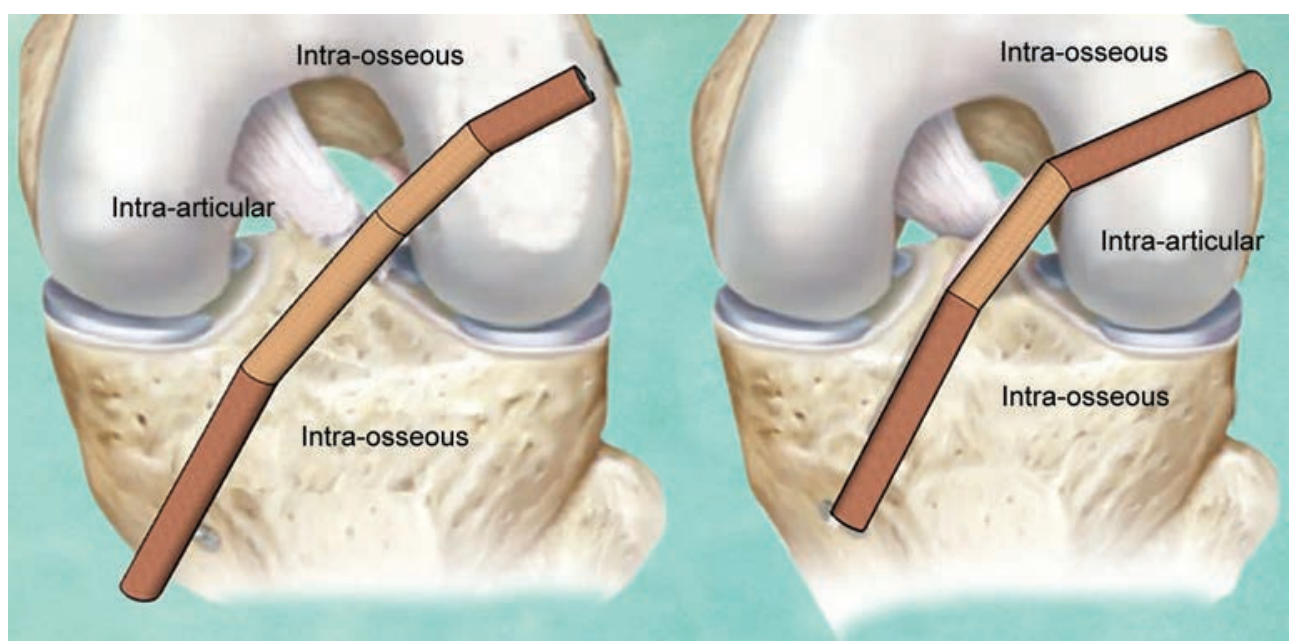

Fig. 1: Angle between the intra and extra part of the graft facing laterally. If deviation occurs in the coronal plan, the new insertion will move more laterally in relation to the primary drilled position and likewise in a sagittal plane where the new insertion will move more posteriorly in relation to the primary drilled position

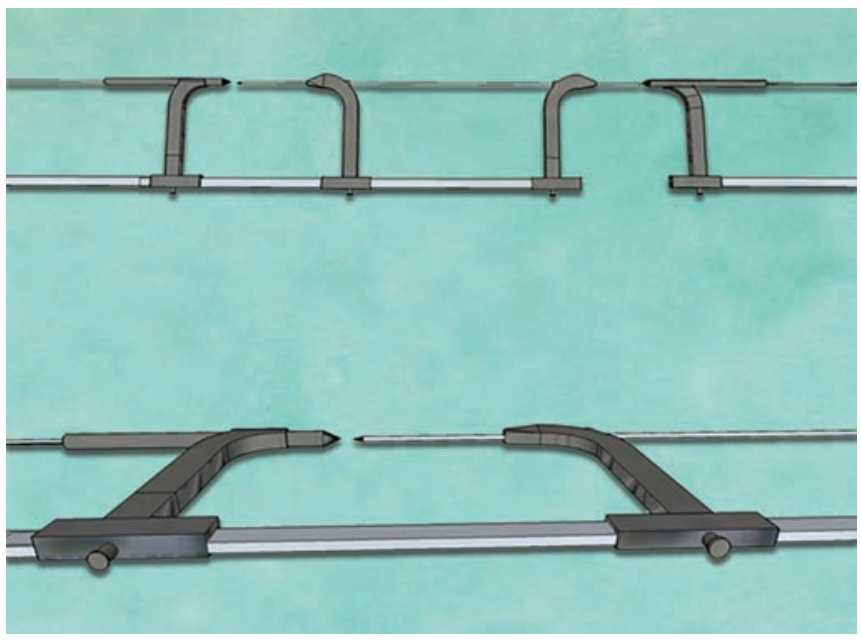

Fig. 2: Suggested conception of a tunnel aimer that keeps the femoral and tibial tunnel in one axis. All four movable aimers slide on a metallic band to keep all aimers in one line and ensure that the guide wires pass from tibia to femur or from femur to tibia in one line

rendering it maloriented and/or loosened. Decrease of the mechanical properties of the graft can be attributed to this deviation (Fig. 1).

Straightening the intraosseous (tibial and femoral) and intra-articular parts of each bundle of the graft eliminates the strain between the graft tissue and the osteochondral tissue at the tunnel entrances.

Though there is no agreement about the exact anatomy of $\mathrm{ACL},{ }^{9,10}$ or about the technique of reconstruction, ${ }^{11}$ the elimination of the angle between the intraosseous and extraosseous parts of the graft at the tunnel entry point in sagittal and coronal planes can be used for all techniques. Factors that affect healing of reconstructed graft of $\mathrm{ACL}^{12}$ would also have a relation with tunnel widening ${ }^{13}$ and have to be tested.

To create the tunnels to fulfil the above-mentioned conditions, a conception of an aimer can be suggested.

The aimer has four removable sliding guides/ sleeves (Fig. 2). Two intra-articular guides/sleeves and two extra-articular for each bone are present. Similar to the conventional aimer positioning technique, first all guides/sleeves are dismounted from the metallic band of the aimer (Fig. 3).

Start by introducing and keeping the first intra-articular guide/sleeve in contact with the footprint of the first bone followed by the second intra-articular guide/sleeve on that of the second bone. Once the appropriate position is selected, the knee flexion angle is maintained while we

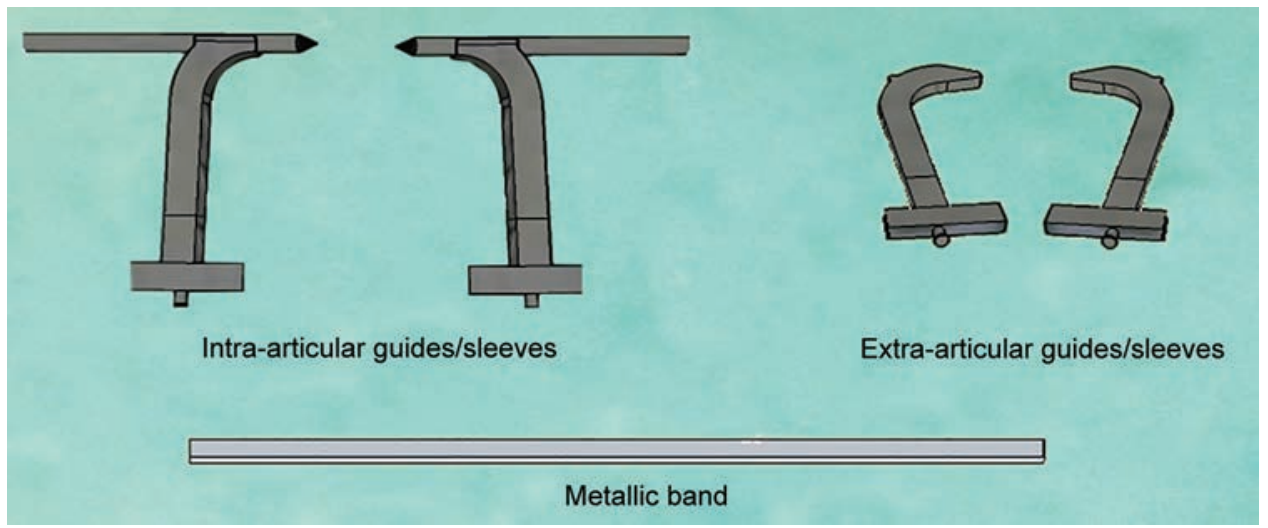

Fig. 3: All guides/sleeves are dismounted from the metallic band of the aimer 
amount and fix the metallic band on both intra-articular guides/sleeves as well as during extra-articular guides / sleeves mounting for each bone.

\section{REFERENCES}

1. Xu Y, Ao YF. Histological and biomechanical studies of interstrand healing in four strand autograft anterior cruciate ligament reconstruction in a rabbit model. Knee Surg Sports Traumatol Arthrosc 2009 Jul;17(7):770-777.

2. Junkin DM Jr, Johnson DL. ACL tibial remnant, to save or not. Orthopedics 2008 Feb;31(2):154-159.

3. Abebe ES, Moorman CT 3rd, Dziedzic TS, Spritzer CE, Cothran RL, Taylor DC, Garrett WE Jr, DeFrate LE. Femoral tunnel placement during anterior cruciate ligament reconstruction. an in vivo imaging analysis comparing transtibial and 2-incision tibial tunnel-independent techniques. Am J Sports Med 2009 Oct;37(10):1904-1911.

4. Kweon, C.; Lederman, ES.; Chhabra, A. Anatomy and biomechanics of the cruciate ligaments and their surgical implications. In: Fanelli GC, editor. The multiple ligament injured knee. A practical guide to management. Chapter 2. New York: Springer; 2013. p. 17-27.

5. Samitier G, Marcano AI, Alentorn-Geli E, Cugat R, Farmer KW Moser MW. Failure of anterior cruciate ligament reconstruction. Arch Bone Jt Surg 2015 Oct;3(4):220-240.

6. Annual Meeting of the Orthopaedic Research Society. Anaheim, CA. 1999.
7. Karlsson J,Hirschmann MT, Becker R, Musahl V. Individualized ACL surgery. Knee Surg Sports Traumatol Arthrosc 2015 Aug;23(8):2143-2144.

8. Dai B, Mao M, Garrett WE, Yu B. Biomechanical characteristics of an anterior cruciate ligament injury in javelin throwing. J Sport Health Sci 2015 Dec;4(4):333-340.

9. Boisrenoult P, Noailles T, Pujol N, Maqdes A, Beaufils P. Ribbon like appearance of the anterior cruciate ligament: the confirmation. Arthroscopy 2015 Jun;31(Suppl 6):e6-e7.

10. Śmigielski R, Zdanowicz U, Drwięga M, Ciszek B, Ciszkowska-Lyson B, Siebold R. Ribbon like appearance of the midsubstance fibres of the anterior cruciate ligament close to its femoral insertion site: a cadaveric study including 111 knees. Knee Surg Sports Traumatol Arthrosc 2014 Nov;23(11):3143-3150.

11. Dargel J, Schmidt-Wiethoff R, Fischer S, Mader K, Koebke J, Schneider T. Femoral bone tunnel placement using the transtibial tunnel or the anteromedial portal in ACL reconstruction: a radiographic evaluation. Knee Surg Sports Traumatol Arthrosc 2009 Mar;17(3):220-227.

12. Chen C-H. Graft healing in anterior cruciate ligament reconstruction. Sports Med Arthrosc Rehabil Ther Technol 2009 Sep;1:21.

13. Guenther D, Irarrázaval S, Nishizawa $Y$, Vernacchia $C$, Thorhauer E, Musahl V, Irrgang JJ, Fu FH. Variation in the shape of the tibial insertion site of the anterior cruciate ligament: classification is required. Knee Surg Sports Traumatol Arthrosc 2017 Aug;25(8):2428-2432. 